\title{
Searching for the existence of entrepreneurial ecosystems: a regional cross-section growth regression approach
}

\author{
K. Bruns $\cdot$ N. Bosma $\cdot$ M. Sanders $\cdot$ M. Schramm
}

Accepted: 21 March 2017 / Published online: 8 May 2017

(C) The Author(s) 2017. This article is an open access publication

\begin{abstract}
In this paper, we propose a method by which the entrepreneurial ecosystem, if present, reveals itself in the data. We first follow the literature and define the entrepreneurial ecosystem as a multidimensional set of interacting factors that moderate the effect of entrepreneurial activity on economic growth. The quality of such an ecosystem, by its multidimensionality, is impossible to measure directly. But so defined, we argue that variation in entrepreneurial ecosystem quality should result in variation in the estimated marginal effect of entrepreneurial activity on economic growth. Testing for such variation is possible using a combination of a multilevel growth regression and latent class analysis. We motivate and validate our approach in simulated data before illustrating its applicability in a data set covering 107 European NUTS1-2 regions across 16 EU member states. For this dataset, we cannot reject the hypothesis of a homogeneous contribution of entrepreneurship to regional growth. That is, in this dataset, we find
\end{abstract}

\footnotetext{
K. Bruns $(\bowtie) \cdot$ N. Bosma · M. Sanders · M. Schramm Utrecht School of Economics, Utrecht University, Kriekenpitplein 21-22, 3584, EC, Utrecht, The Netherlands

e-mail: K.Bruns@uu.nl

N. Bosma

e-mail: N.S.Bosma@uu.nl
}

M. Sanders

e-mail: M.J.W.L.Sanders@uu.nl

M. Schramm

e-mail: M.Schramm@uu.nl no evidence of statistically significant heterogeneity in the estimated slope coefficients for entrepreneurial activity across regions. There are several possible explanations for this negative result. The two we deem most likely are first that the NUTS1-2 level may not be disaggregated enough to coincide with the relevant boundaries of the entrepreneurial ecosystem. We suspect our method would reveal significant differences across smaller geographical units, but the data unfortunately do not yet allow us to empirically test this hypothesis in a multi-country regional analysis. The second possible explanation is that the growth rates from 2006 to 2014 coincided with the global financial and the European crisis, and during this time, the effect of entrepreneurship on (long-run average) growth overall has been obscured. Our simulations also suggested a third reason. If measurement error is large (in the order of 33 or $0.015 \%$ point annual GDPgrowth), the effects may also have been obscured.

Keywords Institutions - Entrepreneurship - Regional growth $\cdot$ Multilevel model $\cdot$ Latent class model

JEL Classification E02 $\cdot$ L26 $\cdot$ R11 $\cdot$ O43 $\cdot$ O47

\section{Introduction}

The term entrepreneurial ecosystem was coined to refer to those elements in the entrepreneurs' environment that help them to succeed (or not) in their 
efforts to grow a new venture. Even though the analogy with the natural and biological ecosystems cannot be upheld in all details (Holling 2001), the concept has proven very useful to signify those elements directly relevant to the entrepreneurial value chain (Adner and Kapoor 2010; Spigel 2015). The term "ecosystem," however, also suggests a broader scope and extending the concept to the entire set of interdependent actors and factors coordinated in such a way that they enable productive entrepreneurship is in fact required (Stam 2015). This encompassing definition has proven useful in theorizing about the importance of the context in which entrepreneurs operate and led both academics and policy makers to zoom in on the local, regional, and national enablers of entrepreneurship (Audretsch et al. 2015). Measuring (the size and/or quality of) entrepreneurial ecosystems, however, continues to prove a challenge. A first problem with measuring the quality of an ecosystem is that we first have to establish the appropriate ecosystem boundaries.

In nature, ecosystems overlap. Climate is a global system that overlaps with more localized weather systems and the relevant ecosystem boundaries for the habitat of the eagle clearly span the ecosystems of many mice. Economic or entrepreneurial ecosystems arguably share that property. The local entrepreneurial ecosystem is part of the larger regional, national, international, and perhaps truly global ecosystem and although all economic activity is in the end local, there is no reason to assume that the most relevant ecosystem boundaries coincide with any administrative geographic units, however (dis)aggregated they may be. Instead, the relevant ecosystem boundaries depend on the question at hand. Do we want to study the eagles or the mice?

We follow Stam (2015), who puts forward that the entrepreneurial ecosystem is multileveled and proposed an approach building on Andersson and Henrekson (2015). They first define (local) competitiveness as the ability to continuously renew the economic base of the local economy. Then they argue that entrepreneurship (at the local level) is instrumental in maintaining that ability. Following (Baumol 1990) institutions, broadly defined as "the rules of the game" (North 1990), will influence the (local) supply and direction of entrepreneurship. The relevant institutions (Andersson and Henrekson 2015) then identified are clearly "located" at the national level (e.g., rule of law, ease of starting a firm, taxes, property rights, labor market institutions, social security) or the local level (e.g., local and regional taxes and regulations, presence of, e.g., universities and research institutes and local entrepreneurship cultures and skills). Andersson and Henrekson (2015) also argue that one should be able to identify the effects of local entrepreneurial ecosystems in the different effect entrepreneurial activity has on growth across localities, regions, and countries. They conclude that their arguments "suggest that the magnitude of local multipliers and growth effects associated with the local presence of entrepreneurial and knowledge-intensive activities are a function of the local institutional environment. This is a hypothesis that remains to be rigorously tested in empirical work." (Andersson and Henrekson 2015, p.189)

In this paper, we aim to take a first step in empirically testing that hypothesis. More specifically, we test whether the contribution of entrepreneurship differs significantly across regions. If we may refer to the "local institutional environment" as the ecosystem, we focus on the predicted effect of local entrepreneurial ecosystems on the local multipliers/growth effects. If such effects exist, the marginal effect of entrepreneurial activity (measured in several standard ways) on local economic growth would vary systematically with the quality of the (unobserved) entrepreneurial ecosystem. By investigating at what level of geographic aggregation the marginal impact of entrepreneurial activity on growth shows this predicted variation, we can show whether entrepreneurial ecosystem quality matters most at the regional or national level when economic growth is our variable of interest. ${ }^{1}$

We estimate a standard growth regression, both in an OLS specification and in a multilevel specification for 107 European regions. We find that a multilevel model with different intercepts (average growth rates) per country fits our data best. That specification is preferred over the OLS and multilevel specification with varying slope coefficients across countries. In the OLS regression, the average rate of those entrepreneurs that expect high job growth is a positive predictor of economic growth. In the multilevel model, the effect of high job growth entrepreneurship is weaker, only significant at the $10 \%$ level at the regional level,

\footnotetext{
${ }^{1}$ Unfortunately, our data do not yet allow us to investigate this at the local level, but our approach can easily be applied to such more disaggregated data as they become available.
} 
and the country-mean of entrepreneurship does not affect regional growth. To see whether any heterogeneous effect of entrepreneurship exists, we use residuals of the different specifications, with and without controlling for unobserved country differences. We find no evidence, circumstantial or otherwise, for entrepreneurial ecosystems operating either at the regional or national level.

As other researches suggest that the local context does matter and entrepreneurs may have a key role in shaping and developing local entrepreneurial ecosystems (see, e.g., Feldman 2014), we suspect that our data is geographically too aggregated to distinguish the differential impact of local entrepreneurial ecosystems. Our NUTS-1 and 2 level regions may simply be covering diverse local ecosystems, obscuring and confounding the differences that exist within these regions. Given the limited granularity available in the Global Entrepreneurship Monitor (GEM) data we use for our entrepreneurship variables, however, this is not something we can easily resolve in our cross-country study. The main contribution of this paper is therefore the empirical method we propose and we very much encourage those with access to more disaggregated data to repeat our analysis. In the current data set, we must conclude that we fail to find support for any theory that predicts different marginal effects of entrepreneurial activity on growth across (groups of) NUTS-1/2 EU regions. But the search should continue and we hope our method contributes to that.

The remainder of this paper is structured as follows. In the next section, we position our paper in the literature. Section 3 presents our empirical strategy and briefly derives the main equations we estimate. Section 4 presents a simulation exercise to show that our empirical strategy does uncover the pattern we are looking for in a dataset we have created for that specific purpose. Section 5 presents our real world data and shows the empirical results. We conclude with a discussion of these results and agenda for further research.

\section{Entrepreneurial ecosystems, institutions, and regional growth}

Theoretical interest in the role of entrepreneurship in creating economic growth goes far back. Schumpeter (1912) already put entrepreneurship center stage in his Theory of Economic Development by coining the term "creative destruction". In more modern endogenous growth models, such as those developed by Romer (1986) and Lucas (1988), there is no role for entrepreneurship, as they passively commercialize all knowledge that is generated. Aghion and Howitt (1992) created a model where "entrepreneurs" both generate the knowledge and appropriate entrepreneurial rents through entry, while Michelacci (2003) and Acs and Sanders (2012) distinguished between invention and innovation and show that in such a model, entrepreneurship is complementary to knowledge creation and contributes to growth. The empirical evidence in support of such predictions, however, remains mixed (e.g. van Praag and Versloot 2007). As (Glaeser et al. 2010a, p.3) stated: "While it would be hard to imagine a world in which an abundance of entrepreneurs did not strengthen the local economy, the literature documenting this effect is still in its infancy". Empirical results to date are inconclusive for three reasons. First, there is a measurement problem of entrepreneurship, which led to the use of many different proxies for entrepreneurship (Hechavarria and Reynolds 2009; Stenholm et al. 2011). Studies using varying proxies for entrepreneurship (e.g. Audretsch 1995; Carree and Thurik 1998) have found a positive relation overall, but often these results are multiinterpretable. ${ }^{2}$ Second, and closely related, there is heterogeneity within entrepreneurial activity and the effect on growth is not equal for all types of entrepreneurship (Santarelli and Vivarelli 2007; Stam 2009). Research makes a distinction between ambitious entrepreneurship or gazelles (Henrekson and Johansson 2010; Stam et al. 2012) and businesses started at the local level that create little employment growth or economic expansion. For example, Wennekers et al. (2005) find a U-shaped relationship between entrepreneurial activity and economic development, proxied by GDP/capita levels. This finding was explained as labor moving from unproductive entrepreneurship into employment in early stages of

\footnotetext{
${ }^{2}$ For example, Glaeser et al. (2010b) and Carree and Thurik (1998) find a negative correlation between establishment size and employment or productivity growth, respectively. And one of the possible explanations is that small firms are a sign of more entrepreneurship and new startups. But there could be other explanations such as an increase in competition (Nickell 1996; Nickell et al. 1997).
} 
development (higher GDP/cap reduces entrepreneurship) and from employment into growth enhancing innovative entrepreneurship (entrepreneurship causing GDP/cap growth) as development increases. Third, the two-way causality already referred to above already indicates that the effect of entrepreneurship on growth is hard to isolate empirically (e.g., Baumol 1990; Carree and Thurik 2010; Stephens and Partridge 2011; Fritsch and Wyrwich 2014). Entrepreneurship both causes and is caused by GDP (growth), creating an identification problem. In sum, the literature is only beginning to build a consensus on how to measure entrepreneurial activity, what outcomes to expect from what types of entrepreneurial activity, and how to properly identify such effects. But even if that consensus were achieved, the concept of "entrepreneurial ecosystems," on which this special issue is focused, implies that the same entrepreneurship, accurately measured and properly instrumented, should be expected to affect economic growth differently in different contexts. The entrepreneurial ecosystem concept stresses the complex interactions between various environmental factors and entrepreneurial activity in creating economic dynamics. As such, the concept is closely related to literatures on the national (Lundvall 1992; Freeman 1987, 1995; Edquist 1997) and regional systems of innovation (Autio 1998; Cooke 2002; Doloreux 2002) as well as the more mainstream empirical growth literature that is linking economic growth and development to institutional quality (e.g., Easterly 2001; Acemoglu and Robinson 2000; Sokoloff and Engerman 2002; Nunn 2008). These strands of literature share a focus on the enabling conditions for Schumpeter (1942)'s "gales of creative destruction." It is beyond the scope of this paper to survey all that literature here. Instead, we restrict ourselves to establishing the connection with more mainstream empirical growth literature. The main problem in this literature is that institutions develop endogenously with economic growth, and therefore, to identify and isolate the effect empirically, the researcher has to find an exogenous instrument for institutional quality (e.g., Acemoglu et al. 2001). But even if such a satisfactory instrument can be found at the regional and local levels, there is still the problem that no satisfactory measure of institutional quality exists. This problem, we argue, will also haunt empirical research into the impacts and relevance of the entrepreneurial ecosystem. In fact, both concepts are multidimensional complex systems that prove too elusive to be measured directly in a one-dimensional, cardinal number. The proxies that have been used for institutional quality, such as indices of property rights protection, economic freedom, and corruption, inevitably only "measure" a part of the relevant institutional complex and not even accurately so (Rodríguez-Pose 2013), based as they often are on expert opinion and surveys. The same holds for measuring the quality of the entrepreneurial ecosystem. Elaborate indices as for example proposed by Acs et al. (2014) and Szerb et al. (2015) do give us a useful first cross regional comparison of ecosystem quality. But such composite indices, by the way they have been constructed, have the disadvantage that they cannot be used as independent variables to properly identify the moderating effect of ecosystem quality. It will prove even more complicated to find suitable instruments for such complex multidimensional indices if we aim to use them as an independent variable in cross-sectional growth regressions. Here, we therefore propose an alternative strategy for "measuring" the effects of the entrepreneurial ecosystem. To do so, we exploit the assumption that the entrepreneurial ecosystem will affect output and growth through its effect on entrepreneurial activity, which we arguably can observe. That is, assuming the entrepreneurial ecosystem matters for growth, its quality will be systematically correlated with growth and works as a moderating variable on entrepreneurial activity. An example of such moderating mechanisms is as follows: better protection of property rights increases the future expected private gains from entrepreneurship. This may attract more talented entrepreneurs to the region (or country) to start their own business (see, e.g., Johnson et al. 1999; Sobel 2008). Another example is an improvement of financial institutions, enabling a flow of funds from investors to potential entrepreneurs such that they can undertake larger and more ambitious projects, thereby also increasing the effect of entrepreneurial activity on growth (e.g., King and Levine 1993). Informal institutions can also provide a moderating mechanism; an entrepreneurial culture, trust, social capital, and a dense local knowledge network are all likely to contribute to more productive entrepreneurship in a region or locality (Bosma 2013; Andersson and Henrekson 2015). Our approach thus distinguishes itself by researching a channel through which the moderating 
effect of the entrepreneurial ecosystem on growth will become visible in variation in the contribution of observed entrepreneurial activity to growth.

We conclude from the above review that entrepreneurship takes on many shapes and manifests itself in different contextual settings. Consequently, the relation between entrepreneurship and growth will be heterogeneous and not all types of entrepreneurship create economic growth to the same extent in different institutional contexts. As we are not primarily interested in the exact value or even sign of the marginal effect of entrepreneurship itself, however, we may sidestep these issues for now. We make the case that, even if the estimated marginal effect itself is inefficient or biased due to measurement error, impact heterogeneity, and reverse causation, possible differences in the marginal effect of entrepreneurship on growth are caused, by definition, by differences in the regional entrepreneurial ecosystem. In other words, we assume that the presence of an entrepreneurial ecosystem can be deduced from the way it transforms locally available entrepreneurial talent into activity and ultimately economic growth. Thus defined, the first step that is needed to prove the existence of an entrepreneurial ecosystem at the aggregation levels investigated is to show that the marginal effects differ significantly across geographies. Our proposition is that the entrepreneurial ecosystem is what (ever) moderates the effect of entrepreneurial activity on growth. Of course, we do need to consider relevant controls and specify our regional growth regression in such a way that we do not allow omitted variables that explain cross-regional variation in growth and might be correlated with entrepreneurial ecosystem quality to create the illusion of an ecosystem at work. Therefore, all the usual suspects and controls that the literature suggests should be included. If multiple regimes can be identified with regard to the relationship between entrepreneurship and economic growth, we can introduce variables to predict regime membership, in order to find out what constitutes the entrepreneurial ecosystem and to rule out other possible explanations. Capital formation as well as population growth obviously play a role, in the neoclassical growth model and in regional growth accounting (Ciccone 2002). For example, Sala-i Martin (1996) also finds evidence for beta-convergence between regions in the USA, Canada, Japan, and Europe, indicating that initial income should be controlled for in regional growth regressions. However, the largest share of variance in growth across regions has been attributed to productivity differences and innovation. In empirical work on regional growth, we can then distinguish (i) the linear model, (ii) the innovation-systems or learning-region model, and (iii) the knowledge spillovers model. Rodríguez-Pose and Crescenzi (2008) are the first to have nested these models in one empirical specification. They find that knowledge spillovers indeed happen. But they also show that the transmission of tacit knowledge strongly decays with distance, supporting the innovation systems approach. Furthermore, they find that R\&D expenditures only lead to actual innovation and growth if (a) a region can also benefit from extra-regional spillovers, measured by $R \& D$ in neighboring regions, and (b) the territorially embedded institutional environment is conducive to the diffusion of innovation. These results can be related to the geographical clustering literature (Jaffe et al. 1993; Breschi and Lissoni 2003; Bosma et al. 2008) that links the success of certain regions to the formation of a cluster within which companies of the same sector thrive and benefit from agglomeration advantages and knowledge spillovers. Frenken et al. (2007) show that such spillovers are stronger for "related varieties" in "smartly specialized" regional clusters. Reynolds et al. (1994) find that urbanization promotes spillovers. A result that Bosma (2009) confirmed in a multilevel analysis for European regions is also presented in this paper. From the regional growth literature, we take away that it makes sense to control for regional population density, age structure, and industry diversification (Dogaru et al. 2011; Thissen et al. 2011). Other variables, such as the degree of urbanization, labor productivity, the level of human capital, the investment in R\&D, or the level and type of competition, have been mentioned in the literature as possible moderating variables on the effect of entrepreneurship on (job) growth (Fritsch and Mueller 2008; Fritsch and Schroeter 2011; Fritsch and Noseleit 2013a, b; Unger et al. 2011). Our strategy, however, involves first estimating a clean growth residual. That is, we estimate growth that is not explained by entrepreneurship. Including variables that are complement to and therefore possibly endogenously correlated with entrepreneurship would then be undesirable here. It therefore seems inappropriate to include these variables in the first stage of our analysis. Rather, these variables would become relevant if we find 
different classes of regions as they would then potentially explain the class membership in the second stage. The above contributions led us to expect that entrepreneurship is positively correlated with growth at the regional level. There are also reasons to expect this effect to differ across regions. Helsley and Strange (2011) for example show that urbanized cultures are often more conducive to growth-oriented entrepreneurship. When looking at regional performance in general, Eriksson et al. (2013) have distinguished between regions with a "business climate" and regions with a "people climate," finding that both matter for regional performance, but through different channels. Audretsch et al. (2012) classify regions in an explicit way, using the functional specialization theory. In a sample of German regions, they use regional characteristics to determine the industry structure and thereby the specialization into either production or innovation. They find five groups of regions: industrial districts, periphery, industrial agglomeration, urban agglomeration, and urban periphery. The propensity to start a business is highest in groups 1, 4, and 5, and these types of regions are thus said to have an entrepreneurial regime. These papers, however, focus entirely on the effects of specific aspects of the ecosystem on observed entrepreneurial activity. In this paper, we investigate if there are latent regional ecosystem characteristics that affect the contribution to growth of such early stage entrepreneurship (that is, conditional on observing such activity). We can summarize this in the following hypothesis:

Hypothesis: Entrepreneurship is positively correlated with regional growth, but this relationship is moderated by the regional entrepreneurial ecosystem and therefore differs across regions. As the quality of the entrepreneurial ecosystem cannot be measured directly and accurately, this moderation will manifest itself through latent classes of regions that differ with respect to the strength and possibly the sign of this relationship.

\section{Empirical strategy}

We aim to localize the moderating effect of entrepreneurial ecosystems on the relationship between entrepreneurial activity and economic growth and employ a three-step empirical process. First, we need to account for economic growth caused by the "usual suspects" at the national level (Mankiw et al. 1992). We extend the standard growth model with entrepreneurship and the relevant regional controls in an OLS estimation to establish the effect of entrepreneurship on growth at the regional level. Next, we estimate this model in a multilevel specification. Leckie et al. (2010) and Paterson and Goldstein (1992) show that multilevel models are very suitable when a complex web of influences at different levels of aggregation are suspected. This is definitely the case when looking at entrepreneurial ecosystems and formal and informal institutions at the regional and national level in Europe. Estimating our regression in a multilevel model allows us to distinguish between variance in growth rates at the regional and national level, and the extent to which entrepreneurial activity can explain this variance. We then exclude the entrepreneurship variables in both growth regressions and, after obtaining the residuals in these regressions, regress them on our entrepreneurship variable in an unconditional latent class specification. ${ }^{3}$ That allows us to test the hypothesis that the marginal contribution of entrepreneurship to (unexplained) growth differs systematically between (groups of) regions that do not necessarily coincide with countries. This somewhat roundabout way implies we do not allow the coefficients on the usual suspects in the standard growth regression to differ across (classes of) regions. If we find significant latent classes in this approach, this suggests that it is the contribution of entrepreneurship to growth that differs significantly between endogenously determined groups of regions.

The growth literature has emphasized the importance of considering all relevant variables in a growth regression (Sala-i Martin 1994). We base our model on the Mankiw et al. (1992), hereafter MRW model, and we estimate a cross-regional growth regression including the "usual suspects," adding also relevant regional

\footnotetext{
${ }^{3}$ The problem with running the entire regional growth regression is that in a latent class, one quickly exhausts the degrees of freedom and our dataset is necessarily a cross-section because we had to aggregate over years to get entrepreneurship data at the regional level. As we are not primarily interested in heterogeneity in the coefficients of usual suspects, however, we decided to proceed in two steps. This shortcut is less problematic if one can assume that the countries/regions in the dataset are roughly in the same growth regime. For EU countries, that does not seem too far fetched (Bos et al. 2010).
} 
controls. The MRW specification for a cross-sectional growth regression is given by

$$
\begin{aligned}
\frac{\ln Y_{i}(T)-\ln Y_{i}(T 0)}{T-T 0}= & \alpha_{0}+\alpha_{1} s_{i}^{k}+\alpha_{2} s_{i}^{h}+\alpha_{3} n_{i} \\
& +\alpha_{4} \ln Y_{i}(T 0)+\epsilon_{i}
\end{aligned}
$$

where $i$ indexes regions, $s_{i}^{k}$ and $s_{i}^{h}$ are the average shares of income invested in human and physical capital (in the period $T 0-T$ ), respectively, and $n$ is the average growth rate of the population. By including initial income, regions are allowed to be out of the steady state and we can test for convergence. The disadvantage of a growth specification is that permanent productivity differences in the production function across countries and regions end up in the error term. We will control for these differences by estimating the country fixed effect on a multilevel model.

$$
\begin{aligned}
\frac{\ln Y_{i j}(T)-\ln Y_{i j}(T 0)}{T-T 0}= & \alpha_{0}+\alpha_{0 j}+\alpha_{1} s_{i j}^{k}+\alpha_{2} s_{i j}^{h} \\
& +\alpha_{3} n_{i j}+\alpha_{4} \ln Y_{i j}(T 0) \\
& +\epsilon_{i j}
\end{aligned}
$$

where $j$ indexes the country and the specification allows for country-specific intercepts $\alpha_{0 j}$. The MRW model was originally developed to model crosscountry differences in growth rates. From the regional growth literature, we know that several other factors are important when explaining regional growth. These factors include population density, industry structure, and the demographic structure of the region. They are found to aid the conversion of innovation to growth at the regional level. Population density is a commonly used proxy to control for the effect of urbanization economies. The industry structure is important because related variety has been found to contribute to regional growth. Finally, the demographic structure controls for the share of working-age individuals and possible migration that is more relevant within than across countries. We estimated Eq. 3.2 with different combinations of these regional controls. Residual variation, $\epsilon_{i j}$, can be decomposed in a fixed and a random part, which can be used to calculate between and within country variation using the intraclass correlation (ICC) (Snijders and Bosker 2012). This gives us insight into how similar regions within a country are in their growth process. The ICC is the ratio of the variance between countries to the total variance, so it tells us how much of the variance in economic growth is accounted for by clustering on the countrylevel. Note also that the error term now still contains any variation in growth caused by variation in quality of the entrepreneurial ecosystem, either at the regional or national level. But as we have argued above, quality to date has not been quantified and is likely to be inherently unmeasurable. We cannot include a proxy for that latent variable and test explicitly the hypothesis that its marginal effect on growth is positive. We can include, however, proxies for the level of entrepreneurial activity that are common in the literature. If we extend the OLS growth regression by adding the entrepreneurial variables of interest, the regression equation becomes

$$
\begin{aligned}
\frac{\ln Y_{i}(T)-\ln Y_{i}(T 0)}{T-T 0}= & \alpha_{0}+\alpha_{1} s_{i}^{k}+\alpha_{2} s_{i}^{h}+\alpha_{3} n_{i} \\
& +\alpha_{4} \ln Y_{i}(T 0)+\alpha_{5} E_{i} \\
& +\epsilon_{i}
\end{aligned}
$$

where $E_{i}$ is our proxy for entrepreneurship. ${ }^{4}$ By comparing the results from this regression to a multilevel specification (that is equivalent to the one in Eq. 3.2 but we do not write out to save on notation), we can test the hypothesis that the marginal effect of entrepreneurship on growth, $\alpha_{5}$, controlling for the usual suspects is different across countries and/or regions within countries.

We then take the residuals from regressions (3.1) and (3.2) (with or without regional controls) and regress these on regional entrepreneurship in a latent class specification that allows for endogenous sorting into regimes $r(=1, \ldots R)$.

$$
\begin{aligned}
\epsilon_{i} & =\beta_{0 r}+\beta_{1 r} E_{i}+\varepsilon_{i} \\
\epsilon_{i j} & =\beta_{0 r}+\beta_{1 r} E_{i j}+\varepsilon_{i j}
\end{aligned}
$$

where $r=1, \ldots, R$ indicates the regime, and $R$ refers to the (exogenous) total number of regimes. Each regime, $r$, has its own $\beta_{0} r$ and $\beta_{1} r$. We can then test for the existence of latent classes in the data following Greene (2007) who suggests a "test-down" strategy to identify the correct number of regimes. By regressing the residuals on entrepreneurship only, we restrict this analysis to finding groups of regions that differ in the marginal contribution of entrepreneurship to unexplained, residual growth variation. We want to stress that the estimated coefficients are likely to be biased

\footnotetext{
${ }^{4}$ We test three.
} 
by endogeneity (entrepreneurship is endogenous to GDP growth) and omitted variable bias (our specification is parsimonious and variables, possibly correlated with the entrepreneurial ecosystem quality, such as religion and geography, are not included). For the purpose of this paper, however, we are only interested in the clustering of data points that the latent class model would suggest. As we have argued above, finding such a clustering in the data would indicate there is a significant variation in the quality of the entrepreneurial ecosystem across regions as it is that quality that moderates the contribution of entrepreneurial activity on regional growth. Before we turn to our results in Section 5, we first describe a calibration exercise we did to test our method.

\section{Testing our methodology}

To ensure our empirical strategy will in fact reveal the existence of variation in the quality of the entrepreneurial ecosystem, conceptualized here as a multidimensional set of unmeasured variables that positively affect or moderate the contribution of entrepreneurial activity on regional economic growth, we first created a fake database containing all the variables on the right-hand side of Eq. 3.3. We generated random numbers drawn from a uniform distribution between 0 and 0.1 for $s_{k}, s_{h}$, and $n_{i}$, where we drew $\ln Y_{i}(T 0)$ from a uniform distribution between 0 and 1 to fill the database. ${ }^{5} \mathrm{We}$ also generated entrepreneurial activity rate by taking a random number from a uniform distribution between 0 and 0.1. All independent variables are thus i.i.d. by construction. We defined our true entrepreneurial ecosystem in three classes by taking

$$
E E S_{i j}=\left(1+E_{i j}\right)^{\text {class }}-1
$$

where class was set to 1 for the first third of the dataset, to 2 in the second, and to 3 in the third. ${ }^{6}$

\footnotetext{
${ }^{5}$ The Stata $^{T M}$.do file for this simulation is available in the online material.

${ }^{6}$ The allocation of our artificial regions to classes was first done by artificial country group. Then we moved 12 random regions from every class to another class to avoid perfect coincidence of class and country. The Stata ${ }^{T M}$.do file in the online material to this paper provides the details and allows the reader to reproduce and change this.
}

Table 1 Simulation results

\begin{tabular}{lcccc}
\hline & 1 & 2 & 3 & 4 \\
& $\sigma^{2}=0.005$ & $\sigma^{2}=0.005$ & $\sigma^{2}=0.03$ & $\sigma^{2}=0.03$ \\
\hline ML ICC & 0.276 & 0.324 & 0.046 & 0.019 \\
AIC 1 class & -6.308 & -2.624 & -4.067 & -4.022 \\
AIC 2 class & -6.652 & -2.720 & -4.050 & -4.037 \\
AIC 3 class & -6.660 & -2.728 & -4.021 & -4.053 \\
AIC 4 class & -6.655 & -2.690 & -3.899 & -4.084 \\
\hline
\end{tabular}

Italicized AIC indicates the preferred specification

We then set the parameters $\alpha_{1-5}=(0.01,0.3,0.3$, $0.4,-0.1,0.2)$ and computed

$$
\begin{aligned}
\frac{\ln Y_{i j}(T)-\ln Y_{i j}(T 0)}{T-T 0}= & \alpha_{0}+\alpha_{1} s_{i j}^{k}+\alpha_{2} s_{i j}^{h}+\alpha_{3} n_{i j} \\
& +\alpha_{4} \ln Y_{i j}(T 0)+\alpha_{5} E E S_{i j} \\
& +\epsilon_{i j}
\end{aligned}
$$

where $\epsilon_{i j}$ was drawn from a normal distribution $N\left(0, \sigma^{2}\right)$ and we tested for different levels of $\sigma$. We also added a more complex and general structure by adding a full set of interaction terms with $E E S_{i j}$ (all with a coefficient of 0.1 ) to see if our empirical strategy would also pick up more complicated and interactive ways of conceptualizing the entrepreneurial ecosystem. ${ }^{7}$ The results of our simulation exercise are presented in Table 1.

It can be seen that after hiding a three-class multilevel structure in our data, the model actually reveals that structure, even if we complicate matters with interaction terms that would capture how the quality of the entrepreneurial ecosystem makes factor accumulation more productive (column 2). In both columns 1 and 2, we see the ICC indicates a high level of intraclass correlation reflecting the fact that class is correlated across countries. We also find, however, that our model fails to find anything when measurement error (the $\sigma^{2}$ for the distribution of the error term) becomes large (columns 3 and 4). Our multilevel and latent class specifications can spot the multilevel and three class structure up to $\sigma^{2}$ of about 0.015 , which is about 0.5 to 0.33 times the mean growth rate in our dataset. This suggests that with measurement error below $33 \%$ of the mean value of growth, our model picks up any systematic variation in the quality

\footnotetext{
${ }^{7}$ We thank an anonymous referee for suggesting these more complex interaction structures as a possibility to us.
} 
of the entrepreneurial ecosystem if it indeed moderates the effect of entrepreneurial activity on regional growth. Our simulations show that this is regardless of whether this contribution to growth is direct or indirect through an interaction effect on the traditional correlates of growth. Having tested and found our method at least in principle and under moderate measurement error to be valid, we can now proceed to analyze the real world data.

\section{Data and results}

\subsection{Data}

Our data comes from Eurostat (2016) and GEM (2016), as is described in Table 2. Our final sample consists of 107 regions in 16 European countries. The bottleneck for our data is the GEM data on entrepreneurship. To get reliable measures of regional entrepreneurship, this data had to be gathered during a 5-year period and mostly at the NUTS-2 level. For some countries, this still did not provide enough observations so the aggregation was scaled up to NUTS-1. In the GEM data set, there are 128 regions in 18 countries and some city regions have been identified at the NUTS-3 level. We reaggregated the GEM data such that these cities are also included in the NUTS2 region in which they are found; this decreases the number of regions slightly but is necessary for consistency. Furthermore, Switzerland and Croatia are in the GEM data set but the former is not part of the European Union and the latter only became a member in 2013, implying that there is no comparable data on the control variables for these countries that can be used together with the available data from Eurostat. A list of all the countries and regions in our sample can be found in the Appendix. Our sample is a good representation of regions in western, northern, and southern Europe. Eastern Europe is somewhat underrepresented as many eastern European countries only joined the European Union in the last few years. We collected data on GDP and the variables in the MRW growth regression for the period 2001 and 2014, or as long as our data sources allowed. As it is a crosssection analysis, the variables that change over time are averages over these years.

Our dependent variable is computed from regional GDP data for each year between 2006 and 2014, taking the difference between the logarithm of GDP in 2006 and 2014 and dividing that by the number of years, $\Delta \ln Y /\left(T-T_{0}\right)$. We also take the logarithm of initial GDP, which is the year 2005, $\ln Y(2005)$. For the share of physical capital investment in income, $s^{k}$, we take the average investment rate, that is the gross fixed capital formation divided by the GDP in that year. At the national level, this is found to be around 0.3 ; in our data set, the mean is 0.21 . Our physical capital data comes from Eurostat (2016). ${ }^{8}$ For the investment in human capital, $s^{h}$, MRW proposed a variable "school," which is formed by multiplying the fraction of the 12-17 aged population that is enrolled in secondary school by the fraction of the working-age population that is in that age bracket, to proxy for the time spent in secondary education. For most European regions, however, secondary education is obligatory until the age of 16 or 17, so we cannot expect much variation there. Therefore, we take the share of the working-age population aged 20-24 and multiply it by the enrolment rates in tertiary education (ISCED 56 ) as percentage of the population aged 20-24. This variable could be seen as a proxy for foregone earnings on the part of the working-age population that is in school. For $n$, we take the logarithmic average population growth. ${ }^{9}$

As the literature suggests not all types of entrepreneurship make the same contribution to growth, we also use three measures of entrepreneurship. Our entrepreneurship variables are taken from the Global Entrepreneurship Monitor (GEM 2016) that conducts representative surveys among the adult population and measures total entrepreneurial activity (TEA) as the share of people who select themselves either as nascent entrepreneurs (actively involved in setting up a business) or as an owner-manager of a new firm existing up to 42 months. For an elaborate account of the methodology and operational details, we refer to Reynolds et al. (2005) and Bosma (2013). GEM

\footnotetext{
${ }^{8}$ For all the averaged variables, we take the average of all available years in the sample period for that region.

${ }^{9}$ In contrast to Mankiw et al. (1992), we do not include $g$, the average growth rate of technical progress, or $\delta$, the average depreciation rate in our regression. Mankiw et al. (1992) assume these variables to be constant across all countries in their data set. That assumption would then hold a fortiori for EU regions and including these constants is only important if the actual size of the estimated coefficients is of interest. We are mostly interested in the between regional variation in the marginal effect of entrepreneurship, which is unaffected by the constant.
} 


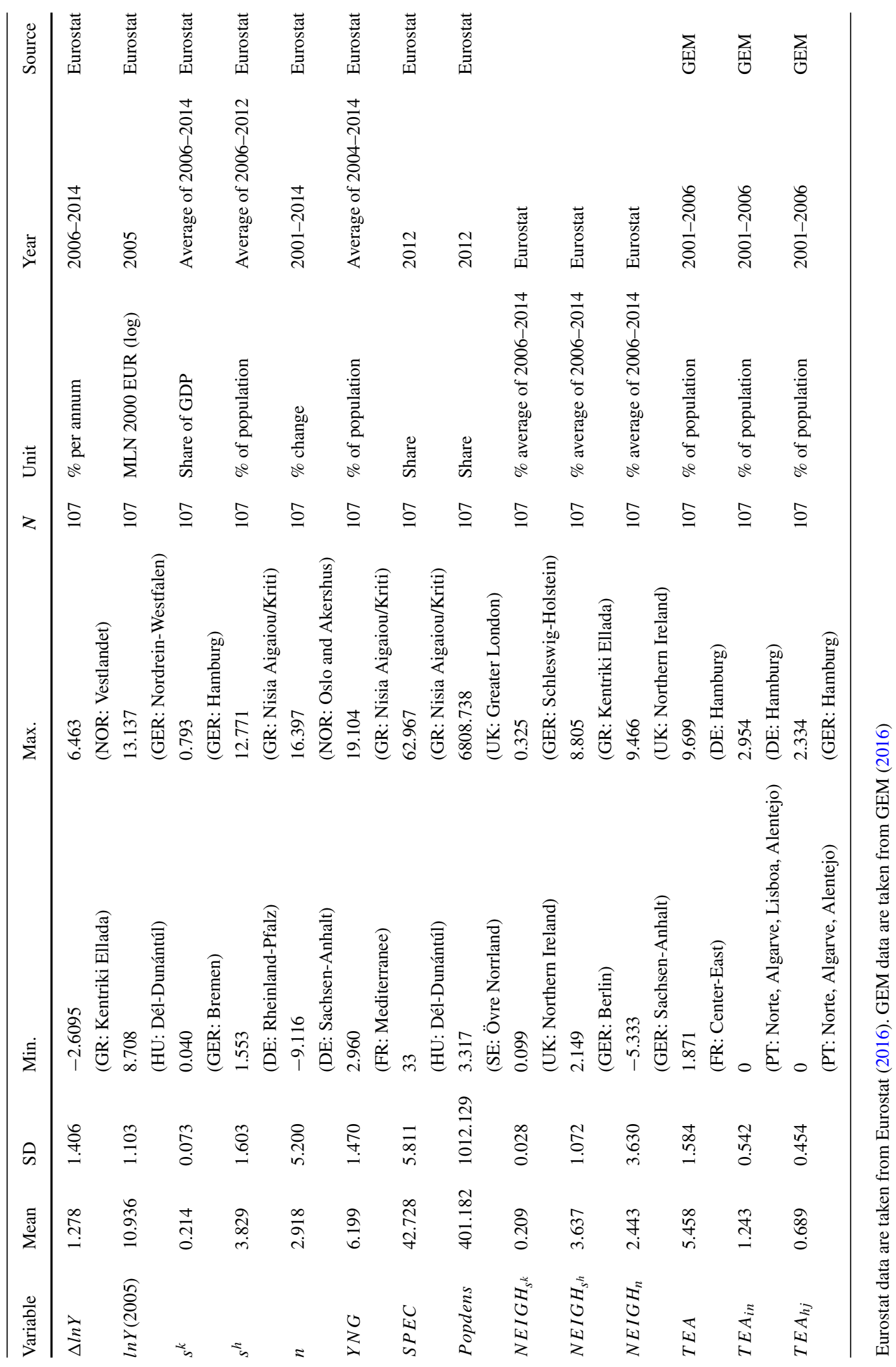


also considers various subcategories of entrepreneurship, of which two are of particular interest for our purpose. Under innovative entrepreneurship ( $\left.T E A_{i n}\right)$, only the entrepreneurs who indicated that their product or service is new to customers and reported that not many competitors are offering the same product or service are included. For entrepreneurs with a high job growth orientation $\left(T E A_{h j}\right)$, early stage entrepreneurs who expect to have 20 or more jobs in their company in the next 5 years are included. To obtain measures at the regional level with acceptable statistical precision, we follow Bosma (2009) who computed regional indicators over six annual GEM waves (between 2001 and 2006) for our European regions. The correlations between these variables are displayed in Table 9 in the Appendix. We see that there are quite some significant correlations between the variables we are interested in. However, none of these correlations are extremely high so multicollinearity is not a problem when running our regressions. Following the literature on regional growth (Dogaru et al. 2011; Thissen et al. 2011), we added controls on population density, regional diversification over industries (SPEC), ${ }^{10}$ and the share of young people between 18 and 34 in the population $(Y N G)$. Finally, we added a vector of variables, $N E I G H$, to control for spillover effects. We identified the neighboring regions for each region and took the average physical capital share of those regions $\left(N E I G H_{s_{k}}\right)$, the average human capital share $\left(N E I G H_{S_{h}}\right)$, and the average population growth $\left(N E I G H_{n}\right)$. We are not interested in the individual signs of these neighbor effects, so we just report whether they are jointly significant.

We observe that the variation in GDP growth rates is large and that all variables fall in the expected range (the mean growth rate in the period 2006-2014 is $1.28 \%$, with a minimum of $-2.61 \%$ for Central Greece and a maximum of 6.46 for West Norway). Growth rates in this period are severely affected by the financial and Eurocrisis, naturally, so these rates are much lower than in preceding years. No severe outliers were detected and all variables are reasonably normally distributed. In Table 9 in the Appendix, we see that of the usual suspects, only population

\footnotetext{
${ }^{10}$ The degree of regional specialization is measured by share in employment of the five largest industries out of total employment. It actually measures specialization, so a high score means high specialization and thus low diversity.
}

growth has a significant and positive correlation with GDP growth, suggesting that at the regional level, the Mankiw-Romer-Weil model is less potent. We also have to note, however, that 9 years is a very short time for the type of long-run growth model that they describe. All three entrepreneurial variables are positively correlated with GDP growth, but only entrepreneurship with a focus on high growth is significant. Naturally, the three types of entrepreneurship are also highly correlated among each other. However, we cannot interpret these correlations as causal relations, as interdependencies between regions in the same country are not accounted for yet and causality in these variables is very likely to run both ways. This will bias the estimated coefficients later on, but should not affect our results on between country or region differences in the correlation coefficients of entrepreneurship with growth.

\subsection{Linear regression and multilevel results}

We first regress all the variables of interest on GDP growth during the entire period in a standard OLS regression with robust standard errors, following the specification from the MRW model. The results are displayed in Table 3. The standard OLS regression (model 1) does not find evidence for a convergence effect of regional GDP between 2006 and 2014; the coefficient has the right sign but is insignificant. This indicates that 9-year growth rates are simply too short to detect significant convergence among regions and the fact that these years are mostly crisis years also obscures the standard convergence dynamics. As our correlation table already suggested, the rate of population growth has a positive effect on the average GDP growth rate. But again, we cannot claim any causality from this finding. It could for example be that fast growing regions also attract more migrants, explaining this positive coefficient. Low migration overall in Europe, however, does suggest the causality runs mostly from population growth to GDP growth. $s^{k}$ and $s^{h}$ do not have significant effects on growth rates. This might be explained by the fact that human capital is high in all European regions or that the mobility of human and physical capital is high such that the explanatory power on growth is not large. Also, the rates of capital and human capital accumulation and specifically physical capital utilization rates may have been seriously affected by the crisis. 
We then ran the OLS regression including the controls suggested in the regional growth literature (model 2). The regional controls include an index of how specialized a region is across sectors $(S P E C)$ and the share of the working-age population that is between 18 and 34, to take into account the demographic structure of the region $(Y N G)$ and population density ( $P O P D E N S$ ), which is a measure of urbanization and market size. Furthermore, to capture spillover effects, we control for the mean levels of the three production inputs of the Mankiw-RomerWeil model (physical and human capital and population growth) of a region's neighboring regions $(N E I G H) .{ }^{11}$ The rationale behind this is that factor mobility between regions may be so high that the growth of these factors in neighboring regions may actually produce growth in other regions.

Out of the regional control variables, SPEC is always negative and highly significant, indicating that more diversified regions have grown faster in these years, which is an intuitive result during crisis years. Furthermore, the effects of neighbor physical, human capital, and population growth are always jointly significant. This effect is mainly driven by population growth in neighboring regions.

The fact that the share of young people has no effect on economic growth is in line with the findings of Rodríguez-Pose and Crescenzi (2008), who also showed that, e.g., life-long learning, the percentage of the labor-force working in agriculture, and the demographic structure of the population are not significant in explaining growth across European regions during roughly the same period.

We then included our proxies for entrepreneurship in columns 3-6. We deviate here from the standard MRW specification, as the other variables are averages over the sample period, whereas our entrepreneurship measures have been collected between 2001 and 2006, so in the preceding period. We do this because Fritsch and Mueller (2008) have found that the effect of entrepreneurship on growth rates often takes up to 10 years to materialize. Furthermore, we want to show that our results are not caused by a simultaneity bias.

Adding the three entrepreneurship measures to the MRW model alters the estimated coefficients of other variables only marginally. Only entrepreneurship with

\footnotetext{
${ }^{11}$ Both within the same country and across national borders where applicable
}

a focus on high growth $\left(T E A_{h j}\right)$ is significant when introduced to the model both individually and jointly with the other two measures. To put things in perspective, note that adding the different entrepreneurship variables to the standard MRW specification explains a mere additional $3-5 \%$ of the unexplained variance. Investments in physical and human capital remain statistically insignificant when entrepreneurship variables are added.

The results obtained from the OLS estimations above, are, however, not to be taken at face value. Contrary to the cross-country analysis of MRW, we are dealing with regions in countries and this creates two challenges; first of all, cross-country variation in the production function will now be absorbed in the constant and residuals. Furthermore, the assumption of identically and independently standard errors will be breached when regions in country A all suffer from lower productivity relative to regions in country B. To incorporate country effects, we will therefore estimate our model in a multilevel regression, using restricted maximum likelihood estimation. In this multilevel specification, we allow the intercept, and thus the mean growth rate, to vary between countries. We tested the standard linear model against the varying-intercept model for all specifications, and the likelihood ratio test statistics show that the country multilevel model should be preferred, both including and excluding entrepreneurship proxies. For several specifications, we also tested whether a varying-slope model should be used for entrepreneurship. These models were rejected in favor of the varying-intercept model.

The results from the multilevel growth regression are presented in Table 4. Again, we first present the MRW model in a multilevel specification (column 2), the convergence effect actually becomes positively significant, meaning that once country-level variation is accounted for in the multilevel model, regions that were richer within the country in 2005 are also the regions that achieved the highest growth rates. This effect does not remain significant, however, when regional controls are introduced. Population growth has again a positive significant effect, and investment in physical and human capital still did not contribute to GDP growth in the period studied. Recall these are crisis years in which under utilization of capital is not uncommon.

The regional controls behave the same as in our OLS model; the degree of specialization has a significant 
Table 3 OLS regression of MRW model with regional controls and entrepreneurship

\begin{tabular}{|c|c|c|c|c|c|c|}
\hline$\Delta \ln Y(2006-2014)$ & 1 & 2 & 3 & 4 & 5 & 6 \\
\hline $\ln Y(2005)$ & $\begin{array}{l}-0.056 \\
(0.134)\end{array}$ & $\begin{array}{l}-0.135 \\
(0.134)\end{array}$ & $\begin{array}{l}-0.219 * \\
(0.125)\end{array}$ & $\begin{array}{l}-0.143 \\
(0.121)\end{array}$ & $\begin{array}{l}-0.158 \\
(0.135)\end{array}$ & $\begin{array}{l}-0.138 \\
(0.135)\end{array}$ \\
\hline$s^{k}$ & $\begin{array}{l}0.337 \\
(1.968)\end{array}$ & $\begin{array}{l}-1.261 \\
(1.408)\end{array}$ & $\begin{array}{l}-1.573 \\
(1.245)\end{array}$ & $\begin{array}{l}-1.291 \\
(1.424)\end{array}$ & $\begin{array}{l}-1.357 \\
(1.273)\end{array}$ & $\begin{array}{l}-1.316 \\
(1.361)\end{array}$ \\
\hline$s^{h}$ & $\begin{array}{l}-0.096 \\
(0.087)\end{array}$ & $\begin{array}{l}-0.077 \\
(0.117)\end{array}$ & $\begin{array}{l}-0.042 \\
(0.115)\end{array}$ & $\begin{array}{l}-0.076 \\
(0.118)\end{array}$ & $\begin{array}{l}-0.059 \\
(0.125)\end{array}$ & $\begin{array}{l}-0.080 \\
(0.117)\end{array}$ \\
\hline$n$ & $\begin{array}{l}0.077 * * * \\
(0.027)\end{array}$ & $\begin{array}{l}0.137 * * * \\
(0.047)\end{array}$ & $\begin{array}{l}0.133 * * * \\
(0.044)\end{array}$ & $\begin{array}{l}0.139 * * * \\
(0.046)\end{array}$ & $\begin{array}{l}0.129 * * * \\
(0.044)\end{array}$ & $\begin{array}{l}0.131 * * * \\
(0.046)\end{array}$ \\
\hline$Y N G$ & & $\begin{array}{l}-4.164 \\
(9.329)\end{array}$ & $\begin{array}{l}-5.106 \\
(8.904)\end{array}$ & $\begin{array}{l}-4.432 \\
(9.274)\end{array}$ & $\begin{array}{l}-3.513 \\
(8.686)\end{array}$ & $\begin{array}{l}-3.545 \\
(9.338)\end{array}$ \\
\hline$S P E C$ & & $\begin{array}{l}-0.118^{* * * *} \\
(0.019)\end{array}$ & $\begin{array}{l}-0.094 * * * \\
(0.021)\end{array}$ & $\begin{array}{l}-0.117 * * * \\
(0.020)\end{array}$ & $\begin{array}{l}-0.103 * * * \\
(0.019)\end{array}$ & $\begin{array}{l}-0.117^{* * * *} \\
(0.019)\end{array}$ \\
\hline POPDENS & & $\begin{array}{l}-0.000 \\
(0.000)\end{array}$ & $\begin{array}{l}-0.000 \\
(0.000)\end{array}$ & $\begin{array}{l}-0.000 \\
(0.000)\end{array}$ & $\begin{array}{l}-0.000 \\
(0.000)\end{array}$ & $\begin{array}{l}-0.000 \\
(0.000)\end{array}$ \\
\hline$N E I G H$ & & $* * *$ & $* * *$ & $* * *$ & $* *$ & $* * *$ \\
\hline$T E A$ & & & $\begin{array}{l}-13.318 \\
(8.0078)\end{array}$ & $\begin{array}{l}-2.117 \\
(8.420)\end{array}$ & & \\
\hline$T E A_{h j}$ & & & $\begin{array}{l}95.453 * * \\
(37.601)\end{array}$ & & $\begin{array}{l}64.604 * \\
(34.253)\end{array}$ & \\
\hline$T E A_{i n}$ & & & $\begin{array}{l}-5.809 \\
(31.589)\end{array}$ & & & $\begin{array}{l}16.165 \\
(24.092)\end{array}$ \\
\hline Constant & $\begin{array}{l}2.107 \\
(1.732)\end{array}$ & $\begin{array}{l}9.606 * * * \\
(3.073)\end{array}$ & $\begin{array}{l}8.808 * * * \\
(2.556)\end{array}$ & $\begin{array}{l}9.871 * * * \\
(2.682)\end{array}$ & $\begin{array}{l}7.111 * * * \\
(1.751)\end{array}$ & $\begin{array}{l}9.166 * * * \\
(2.890)\end{array}$ \\
\hline$R^{2}$ & 0.075 & 0.417 & 0.462 & 0.417 & 0.447 & 0.420 \\
\hline Observations & 107 & 107 & 107 & 107 & 107 & 107 \\
\hline AIC & 377.296 & 339.947 & 337.225 & 341.858 & 336.374 & 341.373 \\
\hline
\end{tabular}

Standard errors in parentheses

$* p<0.10, * * p<0.05, * * * p<0.01$

negative effect, and population density and the demographic structure do not influence regional growth rates. By controlling for unobserved heterogeneity between countries, the spillover effects become much weaker, although they are still significant at the $10 \%$ level. Adding all three entrepreneurship measures jointly does not lead to a significant effect of any of the measures, but when high job-growth entrepreneurship is entered individually, it is still significant at the $10 \%$ level.

We use the Akaike information criterion (AIC), a measure based on the log-likelihood of the model, to see which model is preferred. The standard MRW model without regional controls is the model with the lowest AIC. This means that, within this range of nested models, it is the model with the best fit. It also means that neither regional controls nor entrepreneurship measures can significantly improve upon the standard growth model explaining patterns of regional growth in our sample. Following this, we will use the residuals from the MRW model to test for latent classes, although as a robustness check, we also used the residuals from model 2. Our multilevel specification also allows us to see whether the added variables explain relatively more level 1 or level 2 variation. The intraclass correlation (ICC) can be interpreted as the degree of similarity between two regions that are in the same country (Snijders and Bosker 2012). Or alternatively as the share of the variance that can be attributed to differences at the country level. Var(cons) 
Table 4 Multilevel models

\begin{tabular}{|c|c|c|c|c|c|}
\hline$\Delta \ln Y(2006-2014)$ & 0 & 1 & 2 & 3 & 4 \\
\hline \multicolumn{6}{|l|}{ Fixed effects } \\
\hline \multirow[t]{2}{*}{$\ln Y(2005)$} & & $0.185^{* * *}$ & 0.106 & 0.070 & 0.083 \\
\hline & & $(0.071)$ & $(0.075)$ & $(0.076)$ & $(0.075)$ \\
\hline \multirow[t]{2}{*}{$s^{k}$} & & -0.249 & -0.367 & -0.952 & -0.735 \\
\hline & & $(0.690)$ & $(0.672)$ & $(0.736)$ & $(0.702)$ \\
\hline \multirow[t]{2}{*}{$s^{h}$} & & 0.024 & -0.082 & -0.083 & $-0.093^{*}$ \\
\hline & & $(0.037)$ & $(0.054)$ & $(0.055)$ & $(0.054)$ \\
\hline \multirow[t]{2}{*}{$n$} & & $0.077 * * *$ & $0.097 * * *$ & $0.091 * * *$ & $0.093 * * *$ \\
\hline & & $(0.014)$ & $(0.016)$ & $(0.016)$ & $(0.016)$ \\
\hline \multirow[t]{2}{*}{$Y N G$} & & 6.480 & 7.493 & $7.794 *$ & \\
\hline & & & $(4.609)$ & $(4.574)$ & $(4.530)$ \\
\hline \multirow[t]{2}{*}{$S P E C$} & & & $-0.042 * * *$ & $-0.043 * * *$ & $-0.044 * * *$ \\
\hline & & & $(0.013)$ & $(0.013)$ & $(0.013)$ \\
\hline \multirow[t]{2}{*}{ POPDENS } & & & -0.000 & -0.000 & -0.000 \\
\hline & & & $(0.000)$ & $(0.000)$ & $(0.000)$ \\
\hline$N E I G H$ & & & & $*$ & $*$ \\
\hline \multirow[t]{2}{*}{$T E A$} & & & & -5.02 & \\
\hline & & & & $(5.415)$ & \\
\hline \multirow[t]{2}{*}{$T E A_{h j}$} & & & & 29.577 & $30.307 *$ \\
\hline & & & & $(20.003)$ & $(17.917)$ \\
\hline \multirow[t]{2}{*}{$T E A_{i n}$} & & & & 21.830 & \\
\hline & & & & (19.137) & \\
\hline \multirow[t]{2}{*}{ Constant } & $1.279 * * *$ & -1.035 & 1.486 & 1.582 & 1.599 \\
\hline & $(0.384)$ & $(0.919)$ & $(1.372)$ & (1.379) & $(1.361)$ \\
\hline \multicolumn{6}{|l|}{ Random effects } \\
\hline Var(cons) & 1.514 & 1.303 & 1.301 & 1.316 & 1.296 \\
\hline Var(resid) & 0.567 & 0.421 & 0.417 & 0.417 & 0.417 \\
\hline \multicolumn{6}{|l|}{ Model fit statistics } \\
\hline Observations & 107 & 107 & 107 & 107 & 107 \\
\hline ICC & 0.728 & 0.774 & 0.756 & 0.759 & 0.757 \\
\hline AIC & 246.563 & 217.534 & 219.420 & 229.619 & 258.682 \\
\hline
\end{tabular}

Standard errors in parentheses

$* p<0.10, * * p<0.05, * * * p<0.01$

reports the estimated variance that is attributable to the country level, while Var(resid) reports the residual variance at the regional level. When the former is significantly above zero, as it is for all models including regional controls, this implies country level differences are significant and a multilevel estimation is appropriate.

From the ICC, we see that adding entrepreneurship variable $T E A_{h j}$ to model 2 slightly decreases the ICC, although the difference is very small. This means that entrepreneurship picks up some variance at the between-country level, while the regional variance within countries remains equal. Adding regional control variables to model 2 decreases the ICC. This implies that these controls do better in explaining between-country regional differences than withincountry differences, which is not necessarily what we would expect. Again, it may be explained by high mobility within countries.

We can now investigate whether the effect of entrepreneurship varies between regions inside countries. We do this only for high job growth oriented 
entrepreneurship, as this was the variable with a positive significant effect in the OLS estimation. The intuition is that even though the homogeneous effect of high job growth-oriented entrepreneurship is not significant, it may be significant if we allow for more heterogeneity, for example distinguishing between urban and rural regions. A first way to measure the possible interaction effect is to add the countrylevel mean of high job growth entrepreneurship to the model, as well as the interaction effect between a country's average entrepreneurship rates and the region's deviation from that country mean.

Table 5 shows how the multilevel model is built up. Column 1 presents the null model, including just the intercept. This model shows (again) that the average GDP growth rate over this period is $1.27 \%$. In column 2, we add the mean rate of high job growth entrepreneurship per country to the model, in order to explain some of this country-level variation. The constant, which now corresponds to the GDP growth

Table 5 Multilevel model with fixed and random effects

\begin{tabular}{|c|c|c|c|c|}
\hline & 1 & 2 & 3 & 4 \\
\hline \multicolumn{5}{|l|}{ Fixed effects } \\
\hline cons & $\begin{array}{l}1.279 * * * \\
(0.384)\end{array}$ & $\begin{array}{l}0.788 \\
(0.824)\end{array}$ & $\begin{array}{l}0.786 \\
(0.824)\end{array}$ & $\begin{array}{l}1.945 \\
(1.510)\end{array}$ \\
\hline$T E A_{j g}($ mean $)$ & & $\begin{array}{l}69.359 \\
(102.387)\end{array}$ & $\begin{array}{l}69.541 \\
(102.232)\end{array}$ & $\begin{array}{l}18.330 \\
(89.954)\end{array}$ \\
\hline$T E A_{j g}$ (deviation) & & & $\begin{array}{l}25.151 \\
(86.380)\end{array}$ & $\begin{array}{l}-47.638 \\
(63.719)\end{array}$ \\
\hline$T E A_{j g}($ mean*deviation $)$ & & & $\begin{array}{l}6575.155 \\
(10,651.03)\end{array}$ & $\begin{array}{l}11,300.55 \\
(7721.956)\end{array}$ \\
\hline $\ln Y(2005)$ & & & & $\begin{array}{l}0.066 \\
(0.071)\end{array}$ \\
\hline$s^{k}$ & & & & $\begin{array}{l}-0.585 \\
(0.735)\end{array}$ \\
\hline$s^{h}$ & & & & $\begin{array}{l}-0.091 \\
(0.053)\end{array}$ \\
\hline$n$ & & & & $\begin{array}{l}0.093 * * * \\
(0.016)\end{array}$ \\
\hline$Y N G$ & & & & $\begin{array}{l}6.794 * \\
(4.407)\end{array}$ \\
\hline$S P E C$ & & & & $\begin{array}{l}-0.040 * * * \\
(0.012)\end{array}$ \\
\hline POPDENS & & & & $\begin{array}{l}-0.000 \\
(0.000)\end{array}$ \\
\hline$N E I G H$ & & & & $*$ \\
\hline \multicolumn{5}{|l|}{ Random effects } \\
\hline $\operatorname{Var}(\mathrm{cons})$ & 1.514 & 1.540 & 1.548 & 1.353 \\
\hline $\operatorname{Var}\left(T E A_{J G}\right.$ (deviation) $)$ & & & 117.308 & 68.846 \\
\hline Var(resid) & 0.527 & 0.567 & 0.626 & 0.378 \\
\hline \multicolumn{5}{|l|}{ Model fit statistics } \\
\hline ICC & 0.728 & 0.731 & 0.712 & 0.781 \\
\hline AIC & 246.564 & 237.018 & 191.448 & 200.882 \\
\hline
\end{tabular}

Standard errors in parentheses $* p<0.10, * * p<0.05, * * * p<0.01$ 
Fig. 1 Relation between total early stage job growth-oriented entrepreneurial activity and economic growth

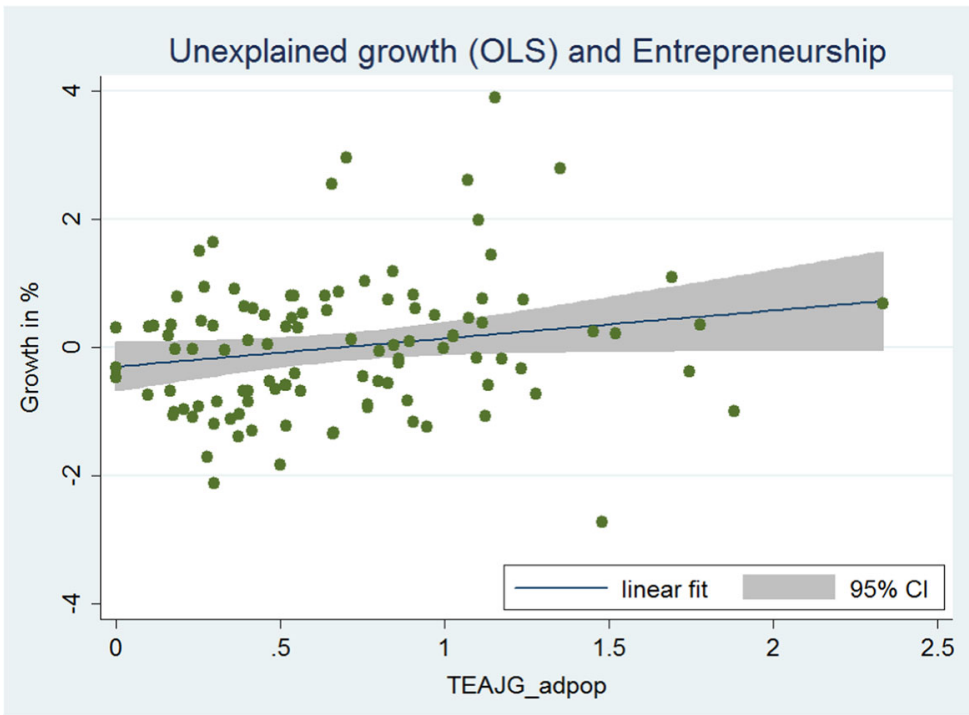

rate in a country with average entrepreneurship levels, is $0.788 \%$. The country average level of entrepreneurship with a focus on high job growth is not significant. Adding the mean rate of entrepreneurship to the multilevel model does increase the ICC, the share of the variance that is explained by the country level, and this makes sense because we added a country-level explanatory variable. In the third column, we add the regional high job growthfocused entrepreneurship rate as deviation from the country mean and an interaction effect with that country-mean. Both are not significant. In column 4, we added all other variables. The control variables that were important in previous estimations have the same sign and significance here, but still the country-level entrepreneurship does not help explain regional growth. The model with the best model fit is the model with only the country-mean, deviation from the mean, and interaction effect of high job growthfocused entrepreneurship. We conclude from this that, when country-level heterogeneity is controlled for, there is no significant homogeneous effect of entrepreneurship on regional growth, and we cannot find evidence for heterogeneous effects of entrepreneurship on growth between regions in different countries.
Fig. 2 Relation between total early stage job growth-oriented entrepreneurial activity and economic growth

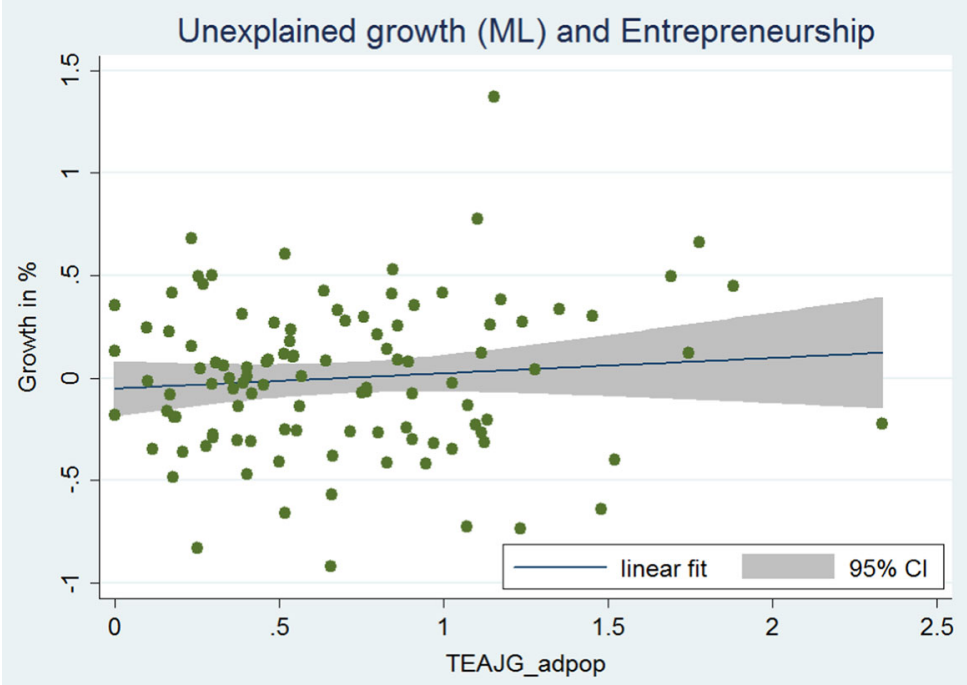


Table 6 Selecting regimes-multilevel residuals

\begin{tabular}{llllll}
\hline & Log-likelihood & Obs & Parameters & AIC & Entrepreneurship significant in classes 1, 2, 3, 4 \\
\hline$T E A$ & & & & & \\
1 class & -52.719 & 107 & 2 & -1.815 & No \\
2 classes & -49.475 & 107 & 7 & 1.056 & No, No \\
3 classes & -44.181 & 107 & 11 & 1.031 & No, No, No \\
$T E A_{\text {in }}$ & & & & & \\
1 class & -52.510 & 107 & 2 & 1.063 & No, No \\
2 classes & -49.891 & 107 & 7 & 1.016 & No, No, No \\
3 classes & -41.965 & 107 & 11 & & \\
$T E A_{h j}$ & & & & -1.819 & No \\
1 class & -52.506 & 107 & 2 & 1.052 & No, - \\
2 classes & -49.510 & 107 & 7 & 1.052 & No,,+ No \\
3 classes & -45.286 & 107 & 11 & & \\
\hline
\end{tabular}

+ significant and positive at the 5\% level, - negative and significant at the 5\% level, No not significant at this level, italics signify the preferred number of classes according to the minimum AIC

We obtained the same results when we add the group mean of total entrepreneurial activity or innovative entrepreneurship in this multilevel regression; the effect of the entrepreneurship is non-significant also when we take the mean, the deviation from the mean, or the interaction effect of those. Therefore, we may conclude that we did not find a robust positive effect of adding entrepreneurship rates to a regional growth regression. There is a positive correlation between regional growth and the number of entrepreneurs that expect high job growth in the future. This variable also has a significant effect in a simple OLS regression, but the effect becomes weaker when we control for unobserved heterogeneity between countries through a multilevel analysis. We cannot yet reject the hypothesis of a heterogeneous relationship between entrepreneurship and economic growth, however. Our multilevel specification does not pick up systematic differences between regions that cluster on other groupings than countries. One might, for example, think of urban versus rural regions, industrial versus agricultural, or larger regional clusters such as Scandinavian, northwestern, southern, and eastern EU regions. To test for the existence of such clusters, we best employ a latent class model.

\subsection{Latent class analysis}

From the standard MRW model, excluding entrepreneurship, we can take the residuals and save these as a measure of "unexplained growth". We know from our analysis above that entrepreneurship has some explanatory power, but so far, we were unable to establish a strong link at the regional level. This should make us pessimistic about finding strong variation in estimated coefficients on entrepreneurship across regions. Still, the objective in this paper is to illustrate a method that would uncover differences in the contribution of entrepreneurship to residual growth across latent classes of regions. A straightforward way of testing this would be to interact the entrepreneurship variable with our moderator of interest, the entrepreneurial ecosystem. However, as already mentioned, this concept cannot (yet) be empirically captured in a meaningful way. Our method allows for this heterogeneity to be found in the data without imposing any regimes or interactions beforehand. Why we do this in a two-step procedure, using the residuals from standard regressions instead of estimating our whole model in a latent class analysis, is because the number of parameters that the latent class analysis (LCA) needs to estimate depends on the product of the number of classes that we want to test and the number of variables introduced in the model. Introducing our whole set of controls in the LCA would leave very few degrees of freedom as we only have 107 observations. We can use residuals from the OLS model, so that we do not control for country effects, or from the multilevel model, where we do. The regressions above showed that in the OLS 
Table 7 Selecting regimes-OLS residuals

\begin{tabular}{llllll}
\hline & Log-likelihood & Obs & Parameters & AIC & Entrepreneurship significant in classes 1, 2, 3, 4 \\
\hline$T E A$ & & & & & \\
1 class & -158.936 & 107 & 2 & 0.170 & No \\
2 classes & -146.109 & 107 & 7 & 2.862 &,-+ \\
3 classes & -142.776 & 107 & 11 & 2.874 &,-+ , No \\
$T E A_{\text {in }}$ & & & & & \\
1 class & -158.743 & 107 & 2 & 0.166 & No \\
2 classes & -148.831 & 107 & 7 & 2.913 &,+ No \\
3 classes & -142.095 & 107 & 11 & 2.862 &,,+- No \\
$T E A_{h j}$ & & & & & \\
1 class & -157.096 & 107 & 2 & 2.136 & + \\
2 classes & -151.868 & 107 & 7 & 2.956 &,+ No, No \\
3 classes & -147.137 & 107 & 11 & & \\
\hline
\end{tabular}

+ significant and positive at the 5\% level, - negative and significant at the 5\% level, No not significant at this level, italics signify the preferred number of classes according to the minimum AIC

regressions, the model with the best fit was the model with regional controls. In the multilevel model, it was the model with only the MRW variables, so we will use the residuals from these models. ${ }^{12}$

For the OLS residuals, the bivariate correlation between unexplained growth and high job growthoriented entrepreneurship is $18.8 \%$ and this is a significant correlation; if we take the residuals from the MRW model, the correlation is even $32.2 \%$. For the multilevel residuals, the correlation with high job growth-oriented entrepreneurship are respectively 5.9 and $8.3 \%$, both not significant at the $10 \%$ level. Figures 1 and 2 show the bivariate relation between residual GDP growth and job growthoriented entrepreneurship, respectively. These Figures show that there is a positive relation between entrepreneurship and cleaned growth, but it mostly disappears once unobserved country-level heterogeneity is controlled for. A visual inspection does not directly hint at the existence of multiple "clouds" of data points that could indicate varying relations between entrepreneurship and regional growth. The latent class analysis in the next section will provide a formal test of this.

\footnotetext{
${ }^{12}$ As a robustness test, we also used the residuals from the MRW-only model for OLS and for the model with all the controls in the multilevel specification, but this did not alter the findings.
}

In order to test this hypothesis, we regressed the two measures for unexplained growth on our three measures of entrepreneurship in six latent class specifications and tested for the existence of multiple regimes in our sample. We compared models with 1 , 2 , and 3 classes on the base of three information criteria. The model that scores the lowest values on these criteria is to be preferred (see Tables 6 and 7).

For both the OLS model residuals and the multilevel residuals, the model selection criteria show that for all three explanatory variables, the model with one class is preferred. We do see that in several of the specifications groups of observations with a positive and a negative effect can be found. But the parsimonious model with only one class still fits our data better. Therefore, in this dataset, we cannot reject the hypothesis that the marginal effect of entrepreneurship on growth is homogenous across all regions, controlling for country fixed effects. ${ }^{13}$

\section{Discussion}

In this paper, we argued that an entrepreneurial ecosystem must reveal itself in the data through

\footnotetext{
${ }^{13}$ In the Appendix, we show in Table 8 the same analysis when using the results of our OLS analysis with only the MRW controls, but the conclusion remains that one class is preferred.
} 
affecting the impact of observed entrepreneurial activity on GDP growth. Then, if ecosystems differ in quality across space, we should be able to reveal the existence and relevance of entrepreneurial ecosystems in the heterogeneity of marginal impacts of entrepreneurial activity on GDP growth at the appropriate geographical level. Finding evidence of such heterogeneity would prove that something is affecting the contribution of entrepreneurship to economic growth differently in different places. We then collected data and designed an empirical strategy to reveal such heterogeneity. We find no support for our hypothesis at the NUTS1-2 aggregation level in our data. But not finding such heterogeneity in this dataset should certainly not be interpreted as proof that the entrepreneurial ecosystem is non-existent. Instead, we can only conclude it does not reveal itself at this level of aggregation.

We simply cannot reject the hypothesis of a homogeneous effect of entrepreneurship in our data. This, however, is not the same as rejecting the hypothesis of a heterogeneous effect. There may be a variety of reasons why our result was found. First, and we deem this most likely, our level of geographical disaggregation may simply be too high for the effects of local ecosystem differences to show up statistically significant. Second, the sample under study might not include enough countries to find a heterogeneous effect. The data is very noisy and from the literature, we already knew that the impact of entrepreneurship itself is hard to properly identify. This then holds a fortiori for any moderation effects on entrepreneurship. The regions we studied may simply not be different enough to find significantly different marginal effects. Third, the period under study is a short period when compared to other empirical growth studies, and the growth rates of European countries in this period have been severely affected by the impacts of the global financial crisis and the Eurocrisis. In an earlier version of this paper, we also ran the analysis on the average growth rate over a much longer period. There, however, we faced the problem that we regress long-run growth on a relatively short sample of entrepreneurial variables observed towards the end of the period. Changing this did not qualitatively change our results. We only find a significant effect of entrepreneurship on growth in our OLS model, where unobserved heterogeneity between countries is not taken into account. And fourth, the countries in the sample are all developed and very much integrated countries, which might imply entrepreneurship and other factors are highly mobile within and even across countries. We tried to control for that by taking into account spillover effects of factor accumulation in neighboring regions, but such mobility would compound the endogeneity problems and reduce the variation in the marginal productivity of entrepreneurial activity across regions. An interesting finding is that the only type of entrepreneurship that has an effect on growth in this study is from the group of entrepreneurs that also expect high job growth in the next years, indicating that the "gazelle hypothesis" (Henrekson and Johansson 2010) also holds for European regions and that entrepreneurs can actually identify themselves as gazelles.

We carried out several robustness checks on our estimations. We tried alternative specifications to control for the country effect, respectively a varyingcoefficient multilevel model and a standard OLS regression with clustered standard errors by country or country dummies. Both models were rejected in favor of the varying-intercept model presented above. Following Gorard (2003) and Leckie et al. (2010) and Paterson and Goldstein (1992), we also recommend in general the use of multilevel models in studies on entrepreneurship and growth, as a multilayered web of influences at different levels of aggregation is at play.

Our results therefore only mean that the regional ecosystems considered here are either not that different or matter little for the contribution of entrepreneurship to regional growth in the period under study. Finally, during the sample period, most European regions have suffered from the global financial crisis, affecting growth rates more than entrepreneurship. This too may confound the long-run effects of ecosystem quality differences. But even as our data do not justify strong conclusions at this stage, we do feel strongly about the appropriateness of our method and consider this the main contribution of this paper. We feel that ecosystem quality proxies cannot (yet) capture the full richness of the entrepreneurial ecosystem, whereas more complex composite indices impose an assumed structure and are not suited as independent variables. Therefore, more studies should make use of latent variables and indirect relations to show the possible moderating effects of ecosystems on innovation and growth before pushing proxies and measures that are supposed to explain that variation directly. Moreover, such analyses may inform data collection efforts 
in the future. If anything, our analysis has shown that collecting entrepreneurial ecosystem data at the NUTS1-2 level may not be the right level of aggregation, and research should focus on national or more local levels of aggregation instead. Establishing where the relevant ecosystem boundaries (do not) lie is an important contribution of our paper also, as it is the first step in collecting better data efficiently in the future.

The challenge remains to make the entrepreneurial ecosystem visible in the data. With better and more complete data, our method may allow us and others to do so in the future.

Acknowledgements We would like to thank Guido Buensdorf, Gabor Peli, Tomasz Mickiewiecz, Andrea Hermann, and participants in the Utrecht workshops on Institutions and Entrepreneurship in 2013 and 2014 as well as participants in the Babson 2013 Entrepreneurship conference for their helpful comments on earlier drafts. All mistakes remain of course our own.

Open Access This article is distributed under the terms of the Creative Commons Attribution 4.0 International License (http:// creativecommons.org/licenses/by/4.0/), which permits unrestricted use, distribution, and reproduction in any medium, provided you give appropriate credit to the original author(s) and the source, provide a link to the Creative Commons license, and indicate if changes were made.

\section{Appendix}

Table 8 Selecting regimes-OLS residuals without regional controls

\begin{tabular}{llllll}
\hline & $\begin{array}{l}\text { Log- } \\
\text { likelihood }\end{array}$ & Obs & Parameters & AIC & $\begin{array}{l}\text { Entrepreneurship } \\
\text { significant in } \\
\text { classes 1,2,3, 4 }\end{array}$ \\
\hline$T E A$ & & & & & \\
1 class & -183.643 & 107 & 2 & 0.632 & No \\
2 classes & -174.819 & 107 & 7 & 3.398 &,-+ \\
3 classes & -168.748 & 107 & 11 & 3.359 &,,-+ No \\
$T E A_{\text {in }}$ & & & & & \\
1 class & -183.472 & 107 & 2 & 0.629 & No \\
2 classes & -177.068 & 107 & 7 & 3.441 &,+ No \\
3 classes & -170.735 & 107 & 11 & 3.397 & No, No, No \\
$T E A_{h j}$ & & & & & \\
1 class & -177.588 & 107 & 2 & 0.519 & + \\
2 classes & -173.142 & 107 & 7 & 3.367 &,++ \\
3 classes & -166.580 & 107 & 11 & 3.319 &,,+++ \\
\hline
\end{tabular}

Italics signify the preferred model specification

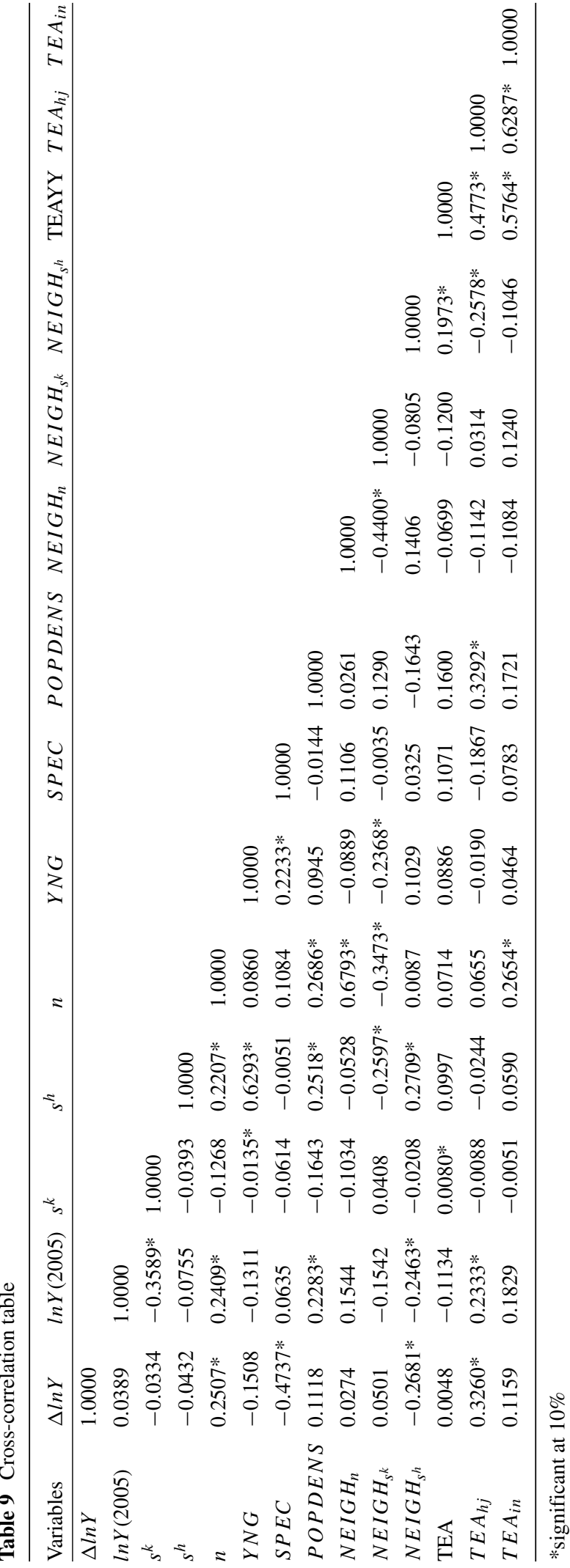




\section{Regions in sample}

\section{Greece}

- Nisi Aigaiou/Kriti

- Voreia Ellada

- Kentriki Ellada

\section{Netherlands}

- Noord Nederland

- Oost-Nederland

- West-Nederland

- Zuid-Nederland

\section{Belgium}

- Brussel

- Vlaams Gewest

- Region Wallone

\section{France}

- Ile de France

- Parisien Bassin

- Nord-Pas de Calais

- East

- West

- South-West

- Center-East

- Mediterranee

\section{Spain}

- Galicia

- Asturias

- Cantabria

- Pais vasco

- Navarra

- La Rioja

- Aragon

- Madrid

- Castilla y León

- Castilla La Mancha

- Extremadura

- Catalunya

- Comm Valenciana

- Baleares

- Andalucia

- Murcia

- Canarias
Hungary

- Central Hungary

- Central Transdanubia

- Western Transdanubia

- Southern Transdanubia

- Northern Hungary

- Northern Great Plain

- Southern Great Plain

Italy

- Nord-Ovest

- Nord-Est

- Centro

- Sud

- Isole

\section{United Kingdom}

- Scotland

- North East

- North West

- Yorkshire Humberside

- East Midlands

- West Midlands

- East Anglia

- Greater London

- South East

- South West

- Wales

- Northern Ireland

\section{Denmark}

- Copenhagen area

- Sjaelland

- Syddanmark

- Nordjylland

- Midtjylland

\section{Sweden}

- Stockholm area

- Östra Mellansverige

- Sydsverige

- Norra Mellansverige

- Mellersta Norrland

- Övre Norrland

- Småland med öarna
- Västsverige

\section{Norway}

- Oslo and surroundings

- Hedmark

- Sor-ostlandet

- Agder og Rogaland

- Vestlandet

\section{Germany}

- Baden-Württemberg

- Bayern

- Berlin

- Brandenburg

- Bremen

- Hamburg

- Hessen

- Mecklenburg-Vorpommern

- Niedersachsen

- Nordrhein-Westfalen

- Rheinland - Pfalz

- Saarland

- Sachsen

- Sachsen-Anhalt

- Schleswig-Holstein

- Thuringen

Portugal

- Norte (incl Porto)

- Algarve

- Centro

- Lisboa e Vale de Tejo

- Alentejo

Ireland

- Border, Midlands and Western

- Southern and Eastern

Finland

- South (Etela-Suomi)

- West/Middle (Lansi-Suomi)

- North (Ita ja Pohjois)

- Helsinki Area (Uusima)

Slovenia

- Vzhodna

- Zahodna 


\section{References}

Acemoglu, D., Johnson, S., \& Robinson, J. (2001). The colonial origins of comparative development: an empirical investigation. American Economic Review, 91, 13691401.

Acemoglu, D.J.S., \& Robinson, J. (2000). The colonial origins of comparative development: an empirical investigation. American Economic Review, 91, 1369-1401.

Acs, Z.J., \& Sanders, M. (2012). Patents, knowledge spillovers, and entrepreneurship. Small Business Economics, 39(4), 801-817.

Acs, Z.J., Szerb, L., \& Autio, E. (2014). National systems of entrepreneurship: measurement and policy. Research Policy Implications, 43(476-494), 43:476-494.

Adner, R., \& Kapoor, R. (2010). Value creation in innovation ecosystems: how the structure of technological interdependence affects firm performance in new technology generations. Strategic Management Journal, 31, 306333.

Aghion, P., \& Howitt, P. (1992). A model of growth through creative destruction. Econometrica, 60, 323-351.

Andersson, M., \& Henrekson, M. (2015). Local competitiveness fostered through local institutions for entrepreneurship. In Audretsch, D.B., Link, A.N., \& Walshok, M.L. (Eds.), The Oxford handbook of local competitiveness, chapter 8 (pp. 145-190). Oxford, United Kingdom: Oxford University Press.

Audretsch, D. (1995). Innovation and industry evolution. Massachusetts: MIT Press.

Audretsch, D., Falck, O., Feldman, M., \& Heblich, S. (2012). Local entrepreneurship in context. Regional Studies, 46, 379-389.

Audretsch, D.B., Link, A.N., \& Walshok, M.L. (2015). The Oxford handbook of local competitiveness. Oxford University Press: Oxford, United Kingdom.

Autio, E. (1998). Evaluation of RTD in regional systems of innovation. European Planning Studies, 6(2), 131-140.

Baumol, W. (1990). Entrepreneurship: productive, unproductive, and destructive. Journal of Political Economy, 893921.

Bos, J.W., Economidou, C., Koetter, M., \& Kolari, J.W. (2010). Do all countries grow alike? Journal of Development Economics, 91(1), 113-127.

Bosma, N. (2009). The geography of entrepreneurial activity and regional economic development. $\mathrm{PhD}$ thesis, $\mathrm{PhD}$ Series at Urban and Regional research centre Utrecht.

Bosma, N., van Stel, A., \& Suddle, K. (2008). The geography of new firm formation: evidence from independent startups and new subsidiaries in the Netherlands. International Entrepreneurship and Management Journal, 4(2), 129146.

Bosma, N.S. (2013). The global entrepreneurship monitor and its impact on entrepreneurship research. Foundations and Trends in Entrepreneurship, 9(2), 143-248.

Breschi, S., \& Lissoni, F. (2003). Mobility and social networks: localised knowledge spillovers revisited. CESPRI Working Papers 142.
Carree, M., \& Thurik, A. (1998). Small firms and economic growth in europe. Atlantic Economic Journal, 26(2), 137146.

Carree, M., \& Thurik, A. (2010). The impact of entrepreneurship on economic growth. Handbook of Entrepreneurship Research, 557-594.

Ciccone, A. (2002). Agglomeration effects in Europe. European Economic Review, 46(2), 213-227.

Cooke, P. (2002). Regional innovation systems: general findings and some new evidence from biotechnology clusters. The Journal of Technology Transfer, 27(1), 133-145.

Dogaru, T., van Oort, F., \& Thissen, M. (2011). Agglomeration economies in european regions: perspectives for objective-1 regions. Tijdschrift voor Economische Sociale Geografie.

Doloreux, D. (2002). What we should know about regional systems of innovation. Technology in society, 24(3), 243-263.

Easterly, W. (2001). The elusive quest for growth: economists' adventures and misadventures in the tropics. MA: MIT press Cambridge.

Edquist, C. (1997). Systems of innovation: technologies, institutions and organizations. Hove, United Kingdom: Psychology Press.

Eriksson, R.H., Hansen, H.K., \& Lindgren, U. (2013). The importance of business climate and people climate on regional performance. Regional Studies, 1-21.

Eurostat (2016). Regional economic accounts.

Feldman, M.P. (2014). The character of innovative places: entrepreneurial strategy, economic development, and prosperity. Small Business Economics, 43(1), 9-20.

Freeman, C. (1987). Technology policy and economic performance: lessons from Japan. Pinter publishers: London, United Kingdom.

Freeman, C. (1995). The national system of innovation in historical perspective. Cambridge Journal of Economics, 19(1), $5-24$.

Frenken, K., van Oort, F., \& Verburg, T. (2007). Related variety, unrelated variety and regional economic growth. Regional Studies, 41, 685-697.

Fritsch, M., \& Mueller, P. (2008). Effects of new business formation on regional development over time: the case of Germany. Regional Studies, 30(8), 15-29.

Fritsch, M., \& Noseleit, F. (2013a). Indirect employment effects of new business formation across regions: the role of local market conditions, 92, 361-382.

Fritsch, M., \& Noseleit, F. (2013b). Investigating the anatomy of the employment effect of new business formation. 37:349Ü377.

Fritsch, M., \& Schroeter, A. (2011). Why does the effect of new business formation differ across regions?, 36, 383-400.

Fritsch, M., \& Wyrwich, M. (2014). The effect of regional entrepreneurship culture on economic developmentevidence for Germany Jena Economic Research Papers 2014-014, Friedrich-Schiller-University Jena, Max-PlanckInstitute of Economics.

GEM (2016). Global entrepreneurship monitor.

Glaeser, E., Rosenthal, S., \& Strange, W. (2010a). Urban economics and entrepreneurship. Journal of Urban Economics, 67(1), 1-14. 
Glaeser, E.L., Kerr, W.R., \& Ponzetto, G.A. (2010b). Clusters of entrepreneurship. Journal of Urban Economics, 67, 150168

Gorard, S. (2003). What is multilevel modelling for?, 51, 46-63. Greene, W. (2007). LIMDEP Version 9.0: Reference guide. Econometric Software, Inc.

Hechavarria, D.M., \& Reynolds, P.D. (2009). Cultural norms \& business start-ups: the impact of national values on opportunity and necessity entrepreneurs. International Entrepreneurship and Management Journal, 5, 417-437.

Helsley, R., \& Strange, W. (2011). Entrepreneurs and cities: complexity, thickness and balance. Regional Science and Urban Economics, 41, 550-559.

Henrekson, M., \& Johansson, D. (2010). Gazelles as job creators: a survey and interpretation of the evidence. Small Business Economics, 35(2), 227-244.

Holling, C. (2001). Understanding the complexity of economic, ecological and social systems. Š Ecosystems, 4, 390-405.

Jaffe, A., Trajtenberg, M., \& Henderson, R. (1993). Geographic localization of knowledge spillovers as evidenced by patent citations. The Quarterly Journal of Economics, 108(3), 577-598.

Johnson, S., McMillan, J., \& Woodruff, C. (1999). Entrepreneurs and the ordering of institutional reform: Poland, Romania, Russia, the Slovak Republic and Ukraine compared. European Bank for Reconstruction and Development.

King, R.G., \& Levine, R. (1993). Finance, entrepreneurship and growth. Journal of Monetary Economics, 32(3), 513-542.

Leckie, G., Pillinger, R., Jenkins, J., \& Rasbash, J. (2010). School, family and neighbourhood: which is most important to a child's education. pages 67-70.

Lucas, R. (1988). On the mechanics of economic development. Journal of Monetary Economics, 22(1), 3-42.

Lundvall, B.-A. (1992). National systems of innovation: towards a theory of innovation and interactive learning. Pinter Publishers: London, United Kingdom.

Mankiw, N., Romer, D., \& Weil, D. (1992). A contribution to the empirics of economic growth. The Quarterly Journal of Economics, 107(2), 407-437.

Michelacci, C. (2003). Low returns in R\&D due to lack of entrepreneurial skills. The Econimic Journal, 113(484), 207-225.

Nickell, S. (1996). Competition and corporate performance. Journal of political economy, 724-746.

Nickell, S., Nicolitsas, D., \& Dryden, N. (1997). What makes firms perform well? European Economic Review, 41(3), 783-796.

North, D. (1990). Institutions, institutional change, and economic performance. Cambridge University Press.

Nunn, N. (2008). The long-term effects of Africa's slave trades. The Quarterly Journal of Economics, 123, 139-176.

Paterson, L., \& Goldstein, H. (1992). New statistical methods for analyzing social structures: an introduction to multilevel models, 17, 387-393.

Reynolds, P., Bosma, N., Autio, E., Hunt, S., De Bono, N., Servais, I., Lopez-Garcia, P., \& Chin, N. (2005). Global entrepreneurship monitor: data collection design and implementation 1998-2003. Small Business Economics, 24(3), 205-231.

Reynolds, P., Storey, D., \& Westhead, P. (1994). Cross-national comparisons of the variation in new firm formation rates. Regional Studies, 28(4), 443-456.

Rodríguez-Pose, A. (2013). Do institutions matter for regional development?Regional Studies, 1-14.

Rodríguez-Pose, A., \& Crescenzi, R. (2008). Research and development, spillovers, innovation systems, and the genesis of regional growth in europe. Regional Studies, 42, 51-67.

Romer, P. (1986). Increasing returns and long-run growth. The Journal of Political Economy, 6, 1002-1037.

Sala-i Martin, X. (1994). Cross-sectional regressions and the empirics of economic growth. European Economic Review, 38, 739-747.

Sala-i Martin, X. (1996). Regional cohesion: evidence and theories of regional growth and convergence. European Economic Review, 40, 1325-1352.

Santarelli, E., \& Vivarelli, M. (2007). Entrepreneurship and the process of firms' entry, survival and growth. Industrial and Corporate Change, 16(3), 455-488.

Schumpeter, J. (1912). The economic theory of development. Oxford: Oxford University Press.

Schumpeter, J. (1942). Capitalism, socialism and democracy, (1942) volume 20. London: Routledge.

Snijders, T.A.B., \& Bosker, R.J. (2012). Multilevel analysis: an introduction to basic and advanced multilevel modeling. Sage Publications, Inc.

Sobel, R.S. (2008). Testing Baumol: institutional quality and the productivity of entrepreneurship. Journal of Business Venturing, 23(6), 641-655.

Sokoloff, K.L., \& Engerman, S.L. (2002). Factor endowments, inequality, and paths of development among new world economies. Economica, 3, 41-88.

Spigel, B. (2015). The relational organization of entrepreneurial ecosystems. Entrepreneurship Theory and Practice. doi:10.1111/ etap.12167.

Stam, E. (2009). Entrepreneurship. The international encyclopedia of human geography.

Stam, E. (2015). Entrepreneurial ecosystems and regional policy: a sympathetic critique. European Planning Studies, 23(9), 1759-1769.

Stam, E., Bosma, N., van Witteloostuijn, A., de Jong, J., Bogaert, S., Edwards, N., \& Jaspers, F. (2012). Ambitious entrepreneurship. a review of the academic literature and new directions for public policy. Number 41 in AWT rapport.

Stenholm, P., Acs, Z., \& Wuebker, R. (2011). Exploring country-level institutional arrangements on the rate and type of entrepreneurial activity. Journal of Business Venturing.

Stephens, H., \& Partridge, M. (2011). Do entrepreneurs enhance economic growth in lagging regions? Growth and Change, 42(4), 431-465.

Szerb, L., Acs, Z.J., Ortega-argilés, R., \& Komlosi, E. (2015). The entrepreneurial ecosystem: the regional entrepreneurship and development index. Mimeo. Available at SSRN 2642514. 
Thissen, M., Limtanakool, N., \& Hilbers, H. (2011). Road pricing and agglomeration economies: a new methodology to estimate indirect effects applied to the Netherlands. The Annals of Regional Science, 47(3), 543-567.

Unger, J.M., Rauch A., Frese, M., \& Rosenbusch N. (2011). Human capital and entrepreneurial success: a meta-analytical review. Journal of Business Venturing, 26(3), 341-358. van Praag, C.M., \& Versloot, P.H. (2007). What is the value of entrepreneurship? A review of recent research. Small Business Economics Journal, 29(4), 351-382.

Wennekers, S., van Stel, A., Thurik, R., \& Reynolds, P. (2005). Nascent entrepreneurship and the level of economic development. Small Business Economics, 24, $293-$ 309. 